\title{
HAND2-AS1, PRKAA2 and VLDLR predict the risk of peritoneal metastasis in gastric cancer of different Lauren types based on STEPP analysis
}

\author{
Hui QU ${ }^{1,2,3,4, *}$; RuIChUAN SHI ${ }^{1,2,3,4, *}$; BOWEN YANG ${ }^{1,2,3,4}$; XI CHEN ${ }^{1,2,3,4}$; YUJIA SONG ${ }^{1,2,3,4}$; LINGZI HE ${ }^{1,2,3,4}$; YITING SUN ${ }^{1,2,3,4}$;

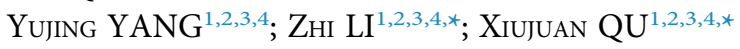 \\ ${ }^{1}$ Department of Medical Oncology, The First Hospital of China Medical University, Shenyang, 110001, China \\ 2 Key Laboratory of Anticancer Drugs and Biotherapy of Liaoning Province, The First Hospital of China Medical University, Shenyang, 110001, China \\ ${ }^{3}$ Liaoning Province Clinical Research Center for Cancer, Shenyang, 110001, China \\ ${ }^{4}$ Key Laboratory of Precision Diagnosis and Treatment of Gastrointestinal Tumors, Ministry of Education, Shenyang, 110001, China
}

Key words: Peritoneal metastasis, Gastric cancer, Lauren, STEPP

\begin{abstract}
The peritoneum is the most common site of recurrence of gastric cancer (GC). Early occult peritoneal metastasis is difficult to detect by imaging examination. Stratifying the risk of peritoneal metastasis in patients with different Lauren subtypes is of great clinical value. We performed a univariate Cox regression to identify those genes with prognostic value of overall survival (OS) and peritoneal-specified disease-free survival (psDFS) from the Gene Expression Omnibus database. The candidate genes were screened by the Subpopulation Treatment Effect Pattern Plot (STEPP) method. Propensity score matching (PSM) analysis was used to reduce the interference of confounders on the results. Based on the optimal cut-off values determined by the STEPP method, we found overexpression of three genes (HAND2-AS1, PRKAA2, and VLDLR) was correlated with shorter 1-year psDFS among patients with diffuse-type than that of patients with intestinal-type GC, and it is highly significant. Gene Set Enrichment Analysis (GSEA) potentially suggested that the three genes promote the early occurrence of peritoneal metastasis in patients with diffuse-type GC through glucose metabolism-related pathways. These three genes may be potential biomarkers. They can be used to assess the risk of peritoneal metastases to guide treatment decisions and follow-up strategies.
\end{abstract}

\section{Introduction}

Gastric cancer (GC) is the fifth most common and lethal cancer in males and females globally and metastasis is its main cause of death (Arnold et al., 2020; Zhang et al., $2020 \mathrm{~b}$ ). Around $40 \%$ of GC patients have distant metastases at the time of diagnosis (Imaoka et al., 2016; Riihimäki et al., 2016). The peritoneum is the most common site of metastases and recurrences in patients with GC (Nishina et al., 2016; Sawaki et al., 2020). Currently, peritoneal metastasis is usually detected using imaging techniques such as computed tomography (CT), ultrasonography, and positron emission tomography/computed tomography (PETCT) (Dong et al., 2019; Honma et al., 2018; Li et al., 2020b;

\footnotetext{
*Address correspondence to: Xiujuan Qu, xiujuanqu@yahoo.com; Zhi Li, zli@cmu.edu.cn

${ }^{\#}$ These authors contributed equally to this work

Received: 21 January 2021; Accepted: 31 March 2021
}

Sawhney and Wilson, 2017). However, peritoneal metastasis may be undetectable in the early stage, and the high radioactivity and economic cost greatly limited its clinical application. Staging laparoscopy can make early diagnosis and tailor-made treatment of peritoneal metastasis, which is great progress in clinical diagnosis of early peritoneal metastasis (Rawicz-Pruszyński et al., 2019). Meanwhile, these examinations do not always provide reliable diagnoses or accurate prognostic predictions, therefore, accurate and less invasive predictive methods are urgently needed.

In GC patients, the patterns of recurrence varied significantly based on the Lauren subtype (Lee et al., 2018). The two Lauren subtypes have unique molecular mechanisms, clinical-pathological features, response to adjuvant chemotherapy, and prognostic risk factors (Lauren, 1965; Rawicz-Pruszyński et al., 2019; Schirren et al., 2020; Wang et al., 2020). Previous studies indicated that diffuse carcinoma is correlated with mutation of RHA and E-cadherin (Lazăr et al., 2008; Liu et al., 2006; 
Machado et al., 2001; Stănculescu et al., 2011; Zhang et al., 2020a). These mutations regulate cell-cell adhesion, allowing GC cells to invade adjacent structures without forming tubules or glands. Therefore, diffuse carcinoma is characterized by an increased risk of metastasis and worse survival. The abnormal expression of caudal type homeobox-2 (CDX-2) gene plays an important role in the development of GC, especially in intestinal-type (Almeida et al., 2005; Asano et al., 2016). Her-2 gene is significantly overexpressed in intestinal gastric carcinoma (Liu et al., 2012). Different molecular mechanisms may contribute to the greater susceptibility of diffuse-type GC to peritoneal metastasis, but there is no consistent conclusion as to its mechanism of action (Bao et al., 2019; Yu et al., 2019). Previous reports mostly predicted the risk of peritoneal metastasis in patients with GC based on genes and some recognised tumour markers (Jeon et al., 2014; Zhao et al., 2020). These biomarkers were screened mainly by differential expression analysis. Differential expression analysis could not prove that high and low expression occurred before and/or after peritoneal metastasis.

Subpopulation Treatment Effect Pattern Plot (STEPP) is a method used to ascertain the treatment-covariate interactions in terms of survival for continuous, binomial, and count data arising from two classifications. Besides, STEPP could define certain subpopulations of the patient based on gene expression, and it visualizes the classification effects estimated within each subpopulation (Baker and Bonetti, 2016; Zou et al., 2019). This enables STEPP to identify the differences in efficacy between subpopulations, thereby guiding clinical diagnosis and treatment.

The purpose of this work was to find the underlying genes and their potential mechanisms that affect the early development of peritoneal metastasis in diffuse-type GC. We used STEPP to compare the peritoneal metastasis between diffuse-type and intestinal-type GC. STEPP and Propensity Score Matching (PSM) analysis were used to improve the credibility of the results. In terms of clinical application, the risk of peritoneal metastasis could be accurately predicted based on the expression status of a few genes.

\section{Materials and Methods}

\section{Patients}

Microarray dataset GSE62254 was downloaded from the Gene Expression Omnibus (GEO) database (http://www.ncbi.nlm. nih.gov/geo/). The Lauren diffuse- or intestinal-type patients with integral clinical characteristics and survival data were included (Cristescu et al., 2015). The following are the inclusion criteria for this study: (1) the patient is older than 18 years; (2) histopathological confirmation of gastric cancer; (3) patients with Lauren classification information; (4) primary gastric cancer tumor specimens at the time of total or subtotal gastrectomy. The following are the exclusion criteria for this study: (1) excluding samples with censored survival data; (2) patients with mixed Lauren classification were excluded. Two hundred and eighty samples were finally included in this study. The RMA algorithm was performed for normalization in the $R$ environment (v3.6.3) (Gautier et al., 2004).
Candidate gene identification and differentially expressed gene analysis

Univariate Cox regression analysis was applied to identify the candidate genes with prognostic value. The Hazard ratios and false discovery rate (FDR) of all genes in the GSE62254 datasets were calculated under the univariate Cox regression. The OS-related genes were filtered by the criteria that the FDR $<0.01$. Differentially expressed genes (DEGs) between patients whose first recurrence site was peritoneal seeding and other patients were screened with the thresholds of $P$ value $<0.05$ using the "edgeR" package in $\mathrm{R}$ (Varet et al., 2016). Then, a Venn diagram was carried out to select the overlapping genes between the two subgroups, OS-related genes and DEG genes, to obtain candidate genes in common.

Univariate Cox regression was also performed on diseasefree survival (DFS), and the resulting overlapping genes with FDR $<0.01$ were defined as related to the occurrence of peritoneal seeding. The OS was defined as the interval between the date of diagnosis and the date of death from any cause. The peritoneal-specified DFS (psDFS) was defined by the time between diagnosis and peritoneal recurrence.

\section{STEPP analysis}

To evaluate whether the peritoneal recurrence risk (in terms of one-year psDFS) difference between diffuse- and intestinaltype) varies according to the gene expressions, the screened candidate genes were analyzed by STEPP. As a graphical tool, the STEPP method was utilized to estimate the difference of peritoneal recurrence risk within each patient based on the continuous values of gene expressions with a sliding window approach (Kensler et al., 2019; Yip et al., 2016; Zou et al., 2019). We used STEPP to determine the cutoff values and divided patients into high- or low-risk groups for peritoneal recurrence in patients with diffuseand/or intestinal-type gastric cancer using $\mathrm{R}$ with package "STEPP". A sensitivity analysis was done to explore the pattern of change in results when the STEPP smoothing parameters $\left(r_{1}\right.$ and $\left.r_{2}\right)$ change. The smoothing parameter $r_{2}$, the minimum number of patients in the subpopulation, takes on 70,120 , or 170 patients out of a total of 280 ; we compute $r_{1}$, the largest amounts of patients in common between two subpopulations, by considering the ratio of $r_{1} / r_{2}$ to be $10 \%$, $30 \%, 50 \%, 70 \%$, and $90 \%$. The number of subpopulations created also changed as values of $\mathrm{r} 1$ and $\mathrm{r} 2$ varied.

The patients were divided into low-expression and highexpression groups according to the cutoff values of gene expressions determined by STEPP. Kaplan-Meier was performed to show the relationships between gene expression levels and one-year psDFS, and the Log-rank test was used to analyze the differences between different gene expression groups.

\section{Analysis of the correlation between genes}

The analysis of correlation was conducted to investigate potential correlations such as upstream and downstream connections, synergistic effects, etc., among the candidate genes.

\section{Propensity Score Matching (PSM) analysis}

In order to reduce the influence of confounding factors, we performed a PSM analysis. The patients were adjusted using the PSM analysis with the nearest-neighbor matching 
method. PSM analysis created two groups of patients with similar numbers of diffuse-type and intestinal-type patients based on their baseline characteristics to minimize differences between baseline clinicopathological factors, which could be a confounding factor in evaluating the effect of Lauren classification (Casadaban et al., 2016; D'Agostino, 1998; Pilotto et al., 2018). The propensity score (PS) for each patient referred to the likelihood that the patient was assigned to a different Lauren classification, which was calculated by covariate adjustment based on clinicpathological information. By using a 1:1 nearest-neighbor matching method, we paired patients to the nearest PS within specified limits and produced two well-matched patient datasets. We used the newly matched patient datasets to validate the effect of gene expression levels in patients with diffuse-type gastric cancer. Kaplan-Meier curves were also conducted in the newly matched dataset.

\section{GSEA}

Gene Set Enrichment Analysis (GSEA) was conducted to explore the potential molecular mechanisms with the three candidate genes. A reference gene set contained the gene sets related to glucose metabolism and lipid metabolism on the Molecular Signatures Database (MSigDB). All steps were performed by the GSEA JAVA program (https://www.gseamsigdb.org/gsea/index.jsp) according to the Pearson method, conditional on the number of analytical substitutions of 1000 . The normalized enrichment score (NES) was the primary statistic for examined gene set enrichment results. $P<0.05$ and false discovery rate $(\mathrm{FDR})<0.25$ were considered statistically significant (Li et al., 2016a; Zhu and Dong, 2018).

\section{Results}

\section{Gene screening}

Fig. 1 showed the main steps in the study. Using the GSE62254 dataset, 280 patients with Lauren diffuse- or intestinal-type were screened by criteria containing integral clinical characteristics and survival data, including 135 patients with diffuse-type GC and 145 patients with intestinal-type GC. The clinical information pertaining to the dataset is summarised in Table 1. Two thousand seven hundred and thirty-two OS-related genes were selected from all genes included in GSE62254 by univariate Cox regression analysis $(\mathrm{FDR}<0.01)$. A total of 155 differentially expressed genes (DEGs) associated with the first recurrence of peritoneal seeding were screened under the criterion whereby $P<0.05$. Then, these two sets of genes were taken to intersect, resulting in a total of 142 genes (Suppl. Fig. S1). Univariate Cox regression revealed that these 142 genes were associated with the recurrence of the peritoneum as the first metastasis sites (FDR $<0.05$ ).

\section{STEPP analysis}

To classify patients into high/low-risk groups for diffuse-type GC, we used STEPP to determine the cut-off values for gene expression values. The 142 genes (mentioned above) were analysed by STEPP with different parameters $\left(r_{1}, r_{2}\right)$, and the appropriate parameters were determined according to previous reports and actual analytical results (Yip et al., 2016). Based on the STEPP analysis results, three significantly impressive genes (HAND2-AS1, PRKAA2, and VLDLR) were selected (Suppl. Table S1, Fig. 2).

The STEPP analysis showed a trend towards significant interaction according to Lauren type (diffuse-type vs intestinal-type of GC) in terms of 1-year psDFS when increasing gene expression. Indeed, with a high value of gene expression, patients with diffuse-type cancer exhibited poorer performance than those with intestinal-type cancer in terms of 1-year psDFS. Therefore, we classified the patients into high-risk and low-risk groups based on the established cut-off value. Based on the established cut-off values of the three genes, 280 patients were divided into high-risk and low-risk groups separately. In the high-risk group, the 1-year psDFS for patients with the diffuse-type of cancer was significantly shorter than that of patients with intestinal-type cancer. In the low-risk group, there was no significant difference between patients with different Lauren types (Fig. 3).

\section{Analysis of the correlation between genes}

In order to reveal the association of these three genes, we paired them pairwise for correlation analysis. The results showed that the correlation of any two of these three genes was statistically significant, but the lower correlation coefficient indicated that their degree of association was not particularly strong $(P<0.001, r<0.5$, Suppl. Table S2). Therefore, we hypothesised that these three genes might not be associated with upstream and downstream effects but jointly promote peritoneal metastasis in GC.

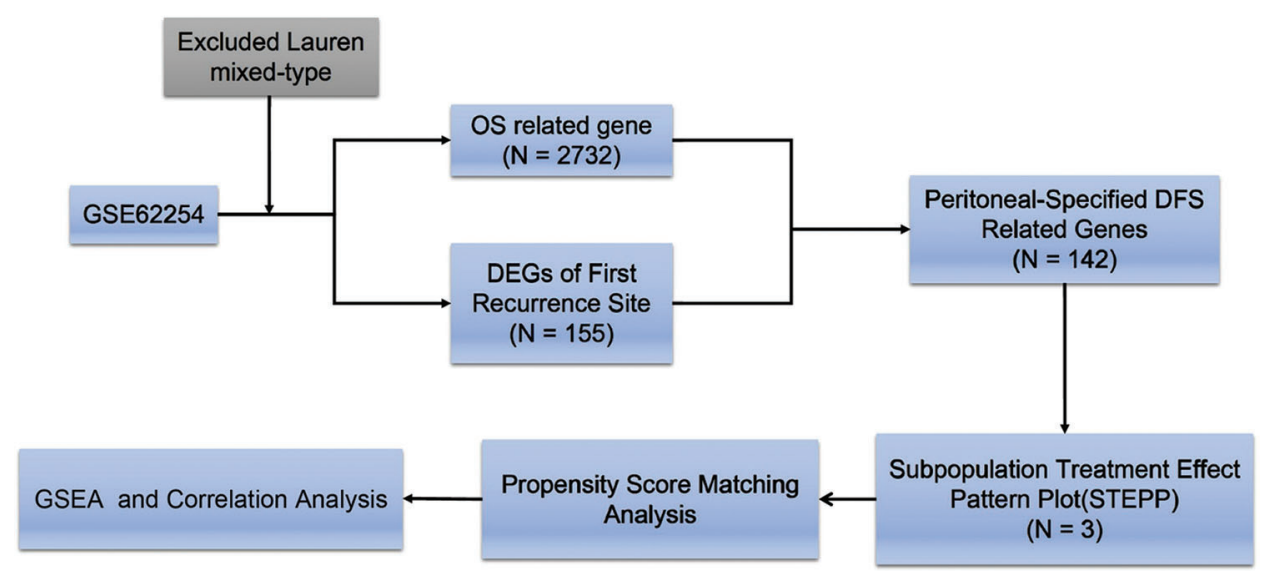

FIGURE 1. Workflow through the steps necessary to this study. Step1: Screening of included samples; Step2: Screening of differentially expressed genes associated with psDFS; Step3: Subpopulation Treatment Effect Pattern Plot Analysis; Step4: Propensity Score Matching Analysis; Step5: Gene-Set Enrichment Analysis and Correlation Analysis. 
TABLE 1

Clinical characteristics of 280 GC patients in the GSE62254 dataset

\begin{tabular}{|c|c|}
\hline Variables & GSE62254 dataset $(\mathrm{N}=280)$ \\
\hline \multicolumn{2}{|l|}{ Sex } \\
\hline Female & $96(34.29 \%)$ \\
\hline Male & $184(65.71 \%)$ \\
\hline \multicolumn{2}{|l|}{ Age } \\
\hline$\leq 63$ & $144(51.43 \%)$ \\
\hline$>63$ & $136(48.57 \%)$ \\
\hline \multicolumn{2}{|c|}{ Borrmann Type } \\
\hline$>1$ & $15(5.36 \%)$ \\
\hline 2 & $95(33.93 \%)$ \\
\hline 3 & $130(46.43 \%)$ \\
\hline 4 & $37(13.21 \%)$ \\
\hline NA & $3(1.07 \%)$ \\
\hline \multicolumn{2}{|l|}{ T Stage } \\
\hline 2 & $174(62.14 \%)$ \\
\hline 3 & $85(30.36 \%)$ \\
\hline 4 & $21(7.5 \%)$ \\
\hline \multicolumn{2}{|l|}{ N Stage } \\
\hline 0 & $36(12.86 \%)$ \\
\hline 1 & $123(43.93 \%)$ \\
\hline 2 & $72(25.71 \%)$ \\
\hline 3 & $49(17.5 \%)$ \\
\hline \multicolumn{2}{|l|}{ M Stage } \\
\hline 0 & $254(90.71 \%)$ \\
\hline 1 & $26(9.29 \%)$ \\
\hline \multicolumn{2}{|l|}{ pStage } \\
\hline I & $28(10 \%)$ \\
\hline II & $91(32.5 \%)$ \\
\hline III & $87(31.07 \%)$ \\
\hline IV & $74(26.43 \%)$ \\
\hline \multicolumn{2}{|c|}{ Tumor Site } \\
\hline Antrum & $144(51.43 \%)$ \\
\hline Body & $101(36.07 \%)$ \\
\hline Cardia & $29(10.36 \%)$ \\
\hline Whole & $6(2.14 \%)$ \\
\hline \multicolumn{2}{|l|}{ Status } \\
\hline Alive & $141(50.36 \%)$ \\
\hline Dead & $139(49.64 \%)$ \\
\hline
\end{tabular}

\section{PSM analysis}

We obtained 184 patients as the new dataset after PSM analysis. There was no statistical difference in the clinicopathological characters between patients with two different Lauren types (Fig. 4a, Table 2). In the new dataset, the 1-year psDFS of patients with diffuse-type GC in the high-risk group was still significantly shorter than that of patients with intestinal-type. In addition, in the low-risk group, there was no significant difference of 1-year psDFS between patients with the two Lauren types (Figs. 4b-4d).
GSEA

To identify signalling pathways differentially affected by the three gene expression levels, GSEA was conducted based on mRNA expressions in the GSE62254 cohort. GSEA results revealed that high expressions of HAND2-AS1, PRKAA2, and VLDLR were associated with cellular glucose homeostasis, glucose-6-phosphate metabolic process, glucose transmembrane transport, cellular glucose metabolic process, and reactive glucose metabolism (FDR $<0.05, P<0.05$; Fig. 5). We selected the most significantly enriched signalling pathways based on the normalised enrichment score (NES). These results confirmed that the three genes promote the early occurrence of peritoneal metastasis in patients with diffuse-type GC through glucose metabolism-related pathways.

\section{Discussion}

Lauren histologic type is a significant factor associated with peritoneal recurrence. Patients with diffuse-type GC are at higher risk of peritoneal metastasis (Dong et al., 2019; Lee et al., 2018; Perrot-Applanat et al., 2019; Stănculescu et al., 2011). We aimed to screen patients with a higher shortterm risk of peritoneal metastasis using the STEPP method. We used STEPP to demonstrate the effects of gene expression levels on the early development of peritoneal metastasis in GC. Besides, through PSM, we attempted to eliminate the interference of confounding factors and ensure the reliability of the results. We found three genes that may promote the early development of peritoneal metastasis in diffuse-type GC and envisaged the mechanism thereof.

The exact molecular mechanisms contributing to the different susceptibility to peritoneal metastasis between Lauren subtypes remains unclear (Bao et al., 2019; Yu et al., 2019). LncRNA HAND2-AS1 was shown to play a tumoursuppressive role in many cancers, such as osteosarcoma, colorectal cancer, lung cancer, leukaemia, oesophageal cancer, endometrial cancer, high-grade serous ovarian carcinoma, and ovarian cancer (Gokulnath et al., 2020; Shi et al., 2020). HAND2-AS1 has been infrequently reported in GC, and the molecular function among different Lauren types remains unclear ( $\mathrm{Li}$ et al., 2020a). In gastric adenocarcinoma cells, HAND2-AS1 could act as a tumoursuppressive factor through inhibiting cell proliferation, migration, and invasion abilities ( $\mathrm{Xu}$ et al., 2020; Yu et al., 2020). Most scholars believe that adenocarcinoma types in the WHO classification were mostly classified as intestinaltype in the Lauren classification. Kawamura et al. (2001) find a difference in the level of expression of glucose transporter 1 (GLUT1) between diffuse-type GC and intestinal-type GC (Kawamura et al., 2001). Chen et al. find that HAND2-AS1 may inhibit the proliferation of osteosarcoma cells by regulating GLUT1 expression (Chen et al., 2019). STK11-PRKAA2-ULK1 and this signalling pathway are also involved in increased migration and cell survival in gastric adenocarcinoma cells (Rao et al., 2017). PRKAA2 is the gene that encodes the a subunit of AMPK. AMPK was found to suppress glucose metabolism, enhance apoptosis, and reduce cell proliferation in GC cells as a tumour-suppressive factor (Chang et al., 2016; Li et al., 2013; Li et al., 2018; Li et al., 2016b). Besides, alterations in 

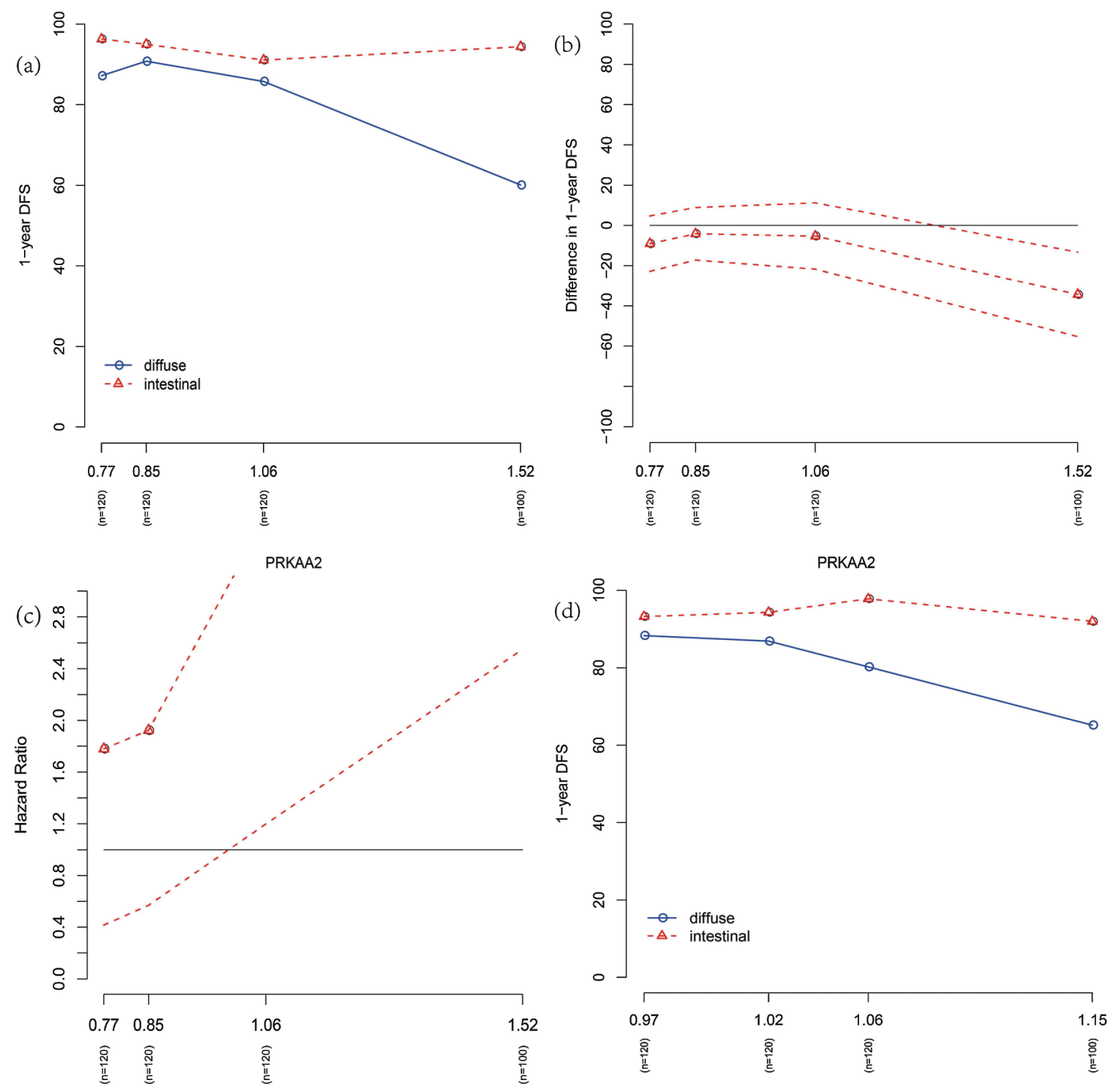

PRKAA2

HAND2.AS1
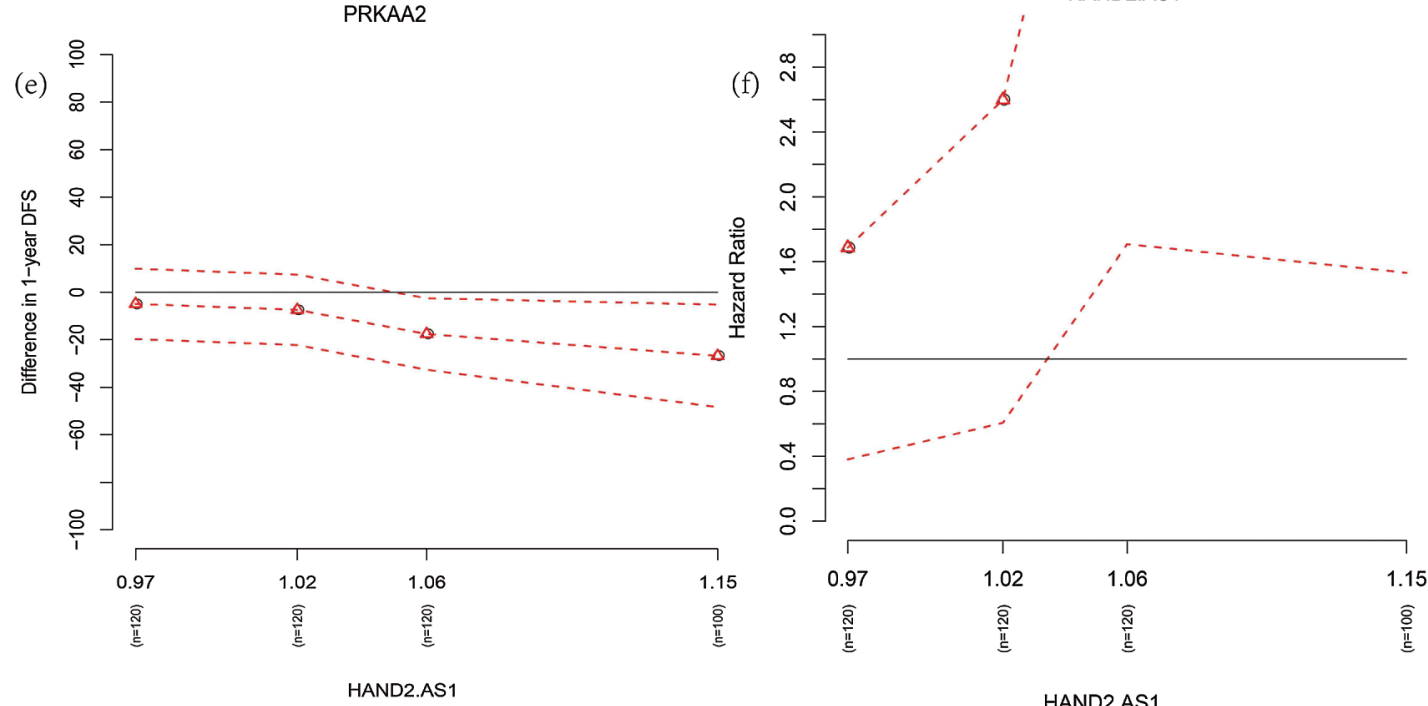

FIGURE 2. (continued)

HAND2.AS1 

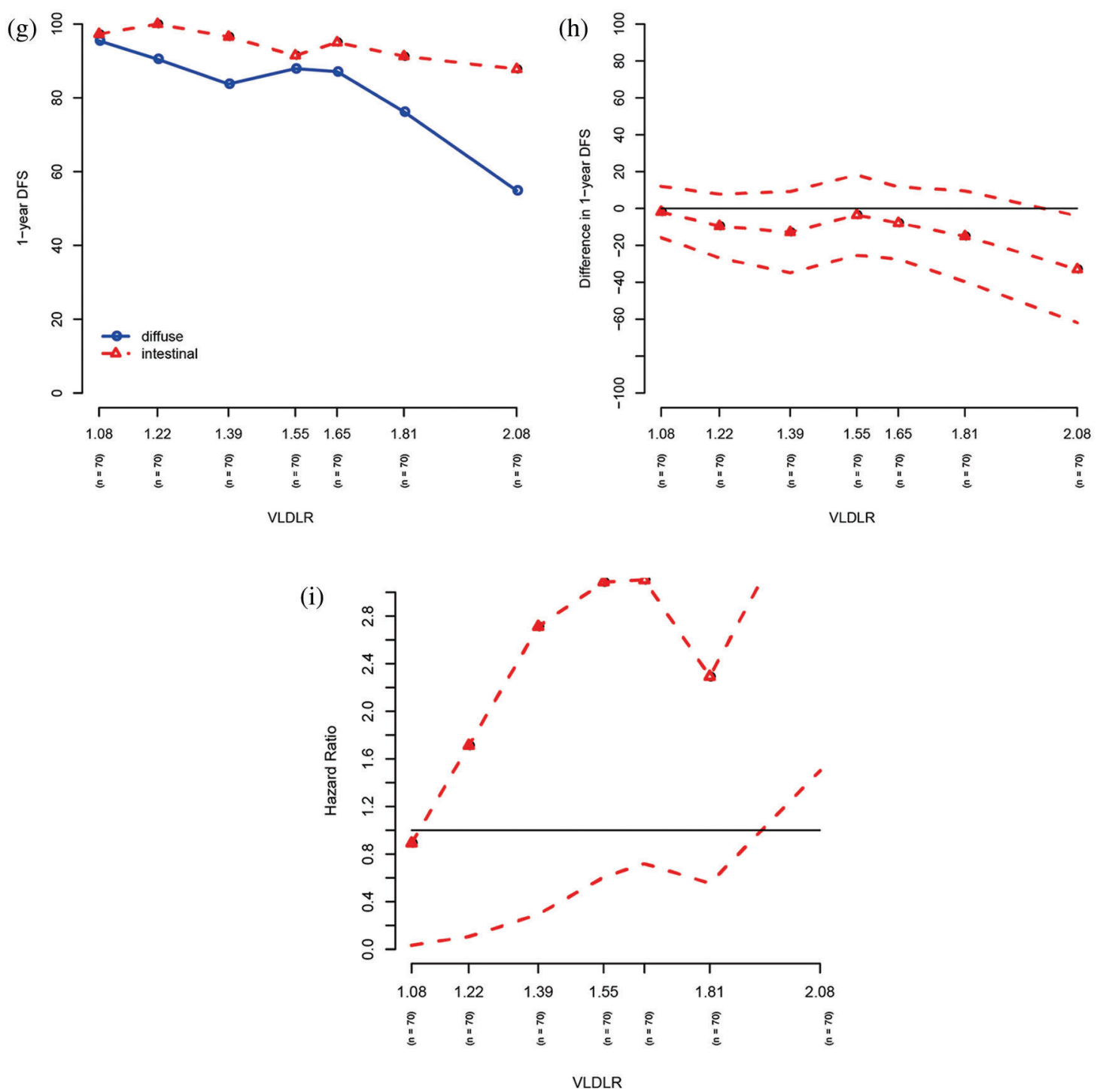

FIGURE 2. Effects of diffuse-type versus intestinal-type GC on 1-year psDFS in the GSE62254 dataset.

STEPP of 1-year psDFS (\%) (a, d, g), the 1-year difference in psDFS (\%) (b, e, h), and psDFS hazard ratio (c, f, i) between patients with diffusetype and intestinal-type GC according to patient subpopulations clustered by PRKAA2 (a-c), HAND2-AS1 (d-f), and VLDLR (g-i).

AMPK can affect VLDLR expression (Zenimaru et al., 2008). VLDLR increases epithelial proliferation and maintains angiogenesis (Oganesian et al., 2008; Rebustini et al., 2012). According to the results of this study and previous reports, we speculated that the three genes, namely HAND2-AS1, PRKAA2, and VLDLR, may lead to early peritoneal metastasis in patients with diffuse-type GC by modulating glucose-lipid metabolism.

In clinical practice, after Lauren classification, the risk of peritoneal metastasis within 1 year could be predicted based on the immunohistochemical results of the three genes. Additionally, for diffuse-type patients with positive expression, the examination of peritoneal metastasis should be improved, and clinicians could thus develop personalised treatment and postoperative follow-up strategies for patients.

Lack of validation of the three gene expressions in pathological specimens represents a key limitation of our study in that it allows the only generation of a hypothesis concerning the role of peritoneal metastasis of the three genes in diffuse-type GC. Based on previous literature and the results presented here, we envisage that these three genes may mediate the early development of peritoneal metastasis in diffuse-type GC through glucose metabolism-related pathways. These results open further perspectives and deserve to be confirmed in further studies. Further experimental validation is needed to explore the specific roles of these three genes. In addition, the low incidence of peritoneal metastasis and the small sample size based on online data are other limitations of this study. We look forward to further verifying our results with larger sample size. Despite these limitations, we believe the results are robust and can be extended to a larger patient population.

The prognosis of these three genes was significantly different between the high and low-expression groups, and these differences were statistically significant. These three genes can be used as biomarkers to predict peritoneal metastasis and guide the choice of chemotherapy regimen by predicting the risk of peritoneal metastasis. This is of great clinical significance. 

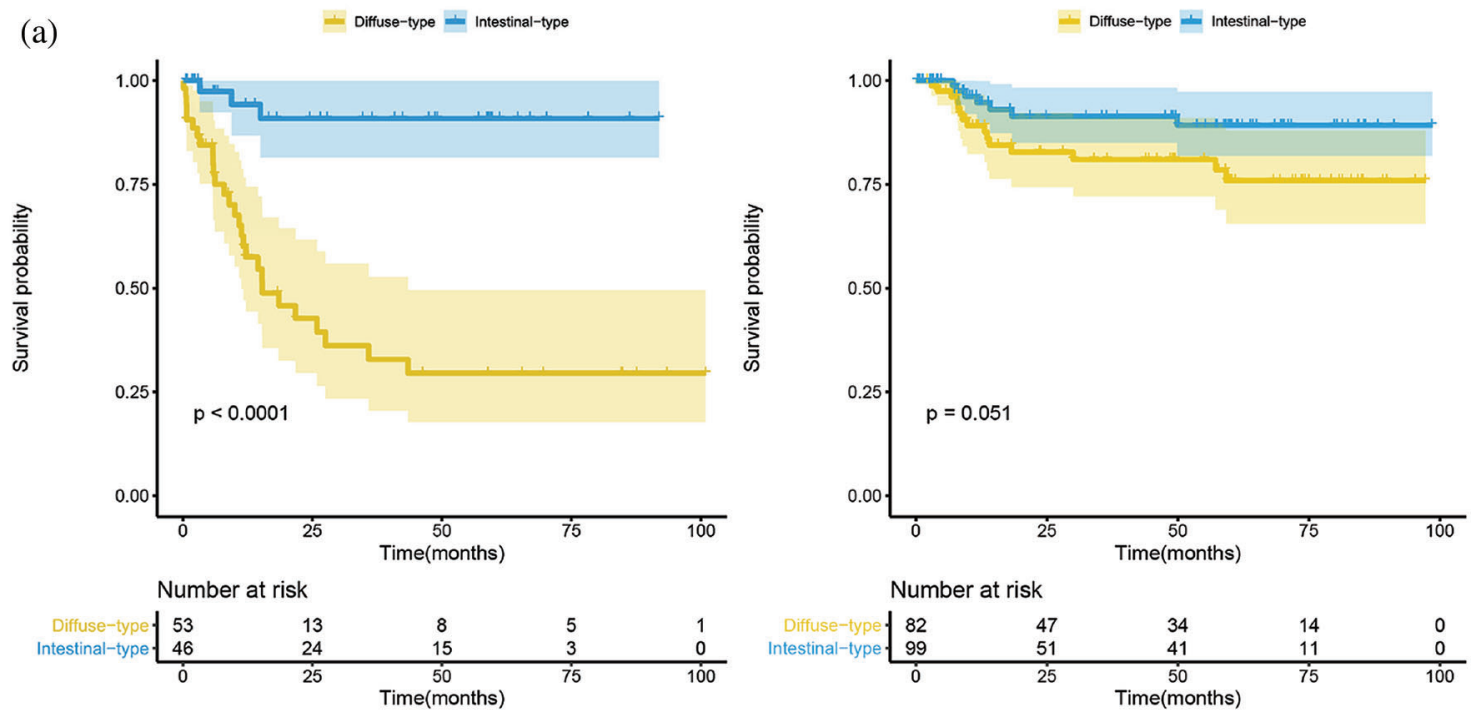

(b)

\pm Diffuse-type $=$ Intestinal-type
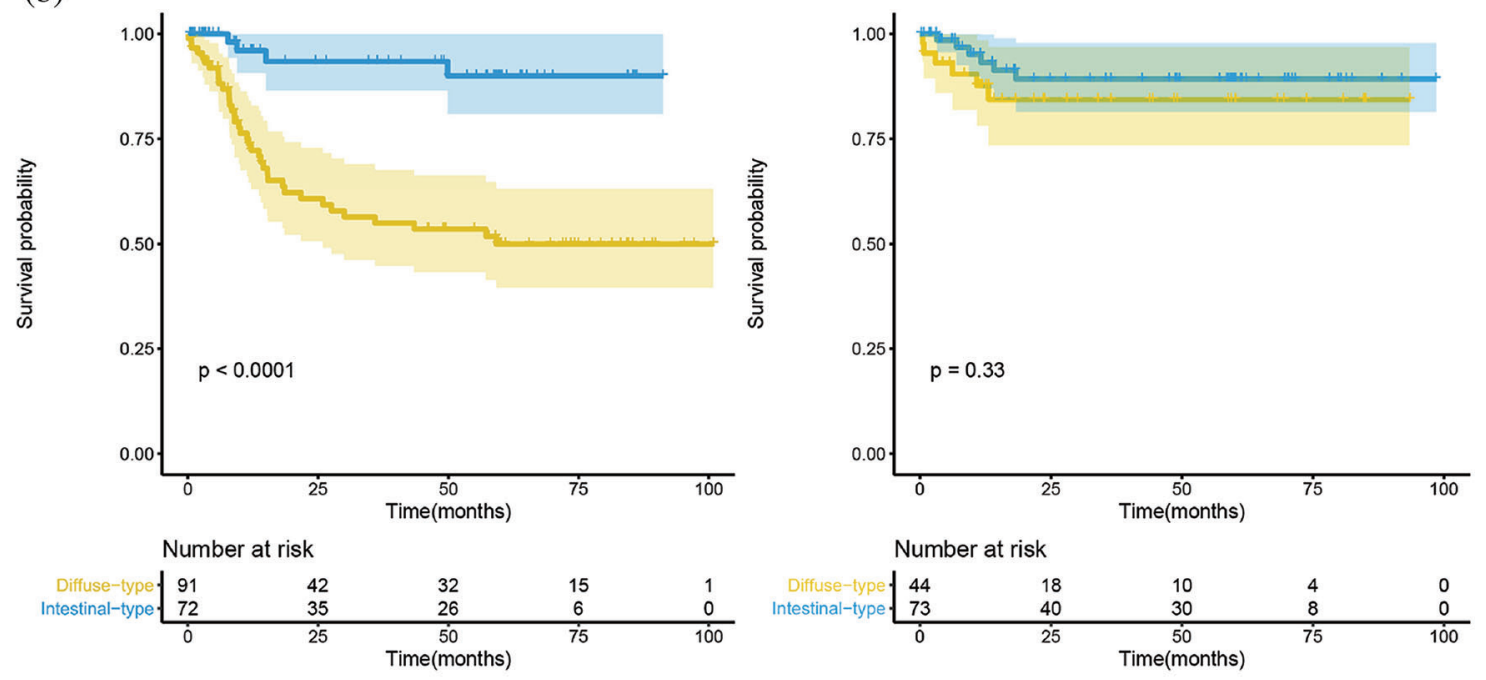

Number at risk

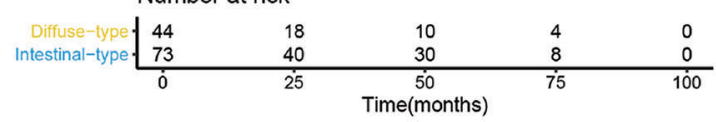

(c)
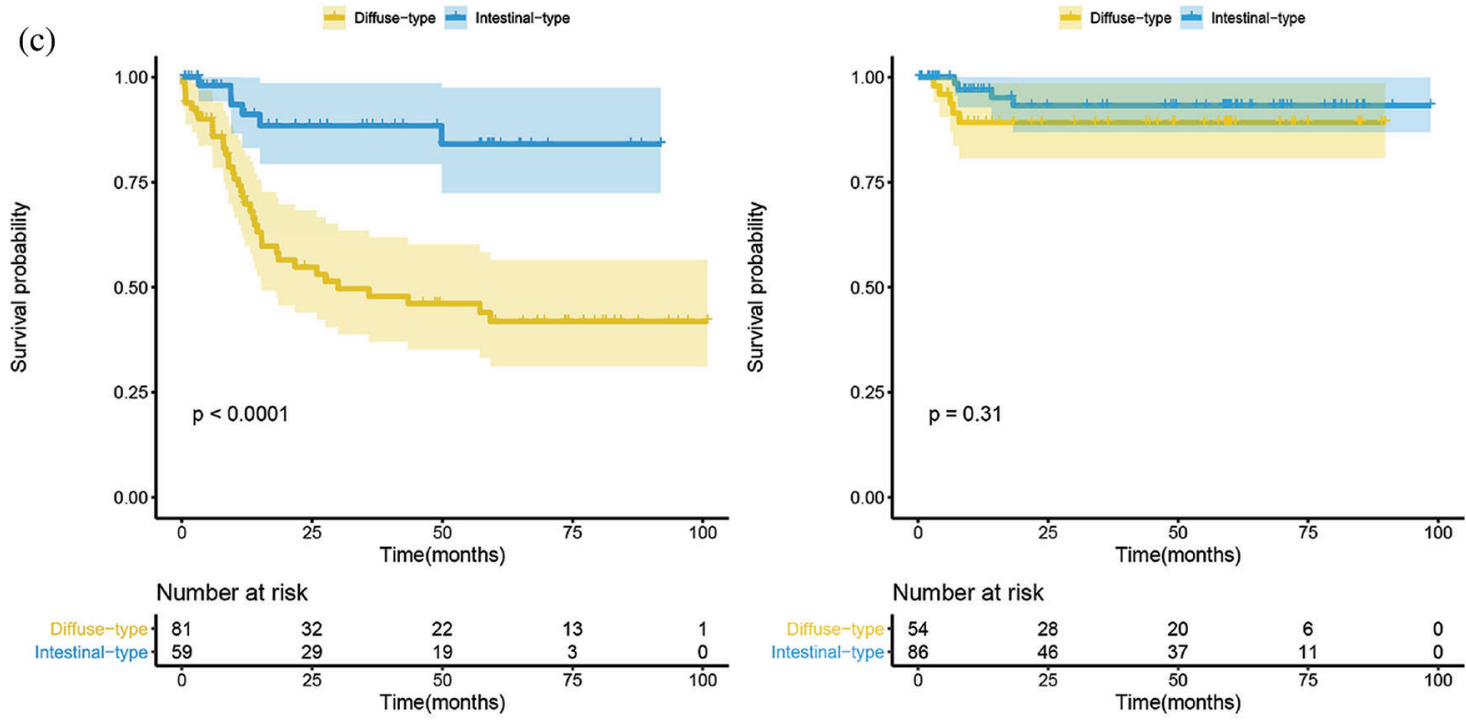

FIGURE 3. Kaplan-Meier survival curves of PRKAA2 (a), HAND2-AS1 (b), and VLDLR (c) between high (left side) and low (right side) expression levels and 1-year psDFS determined by STEPP in patients with diffuse-type and intestinal-type of GC.

The $\mathrm{X}$-axis represents survival time (months), and the $\mathrm{Y}$-axis represents 1-year psDFS. 
(a)

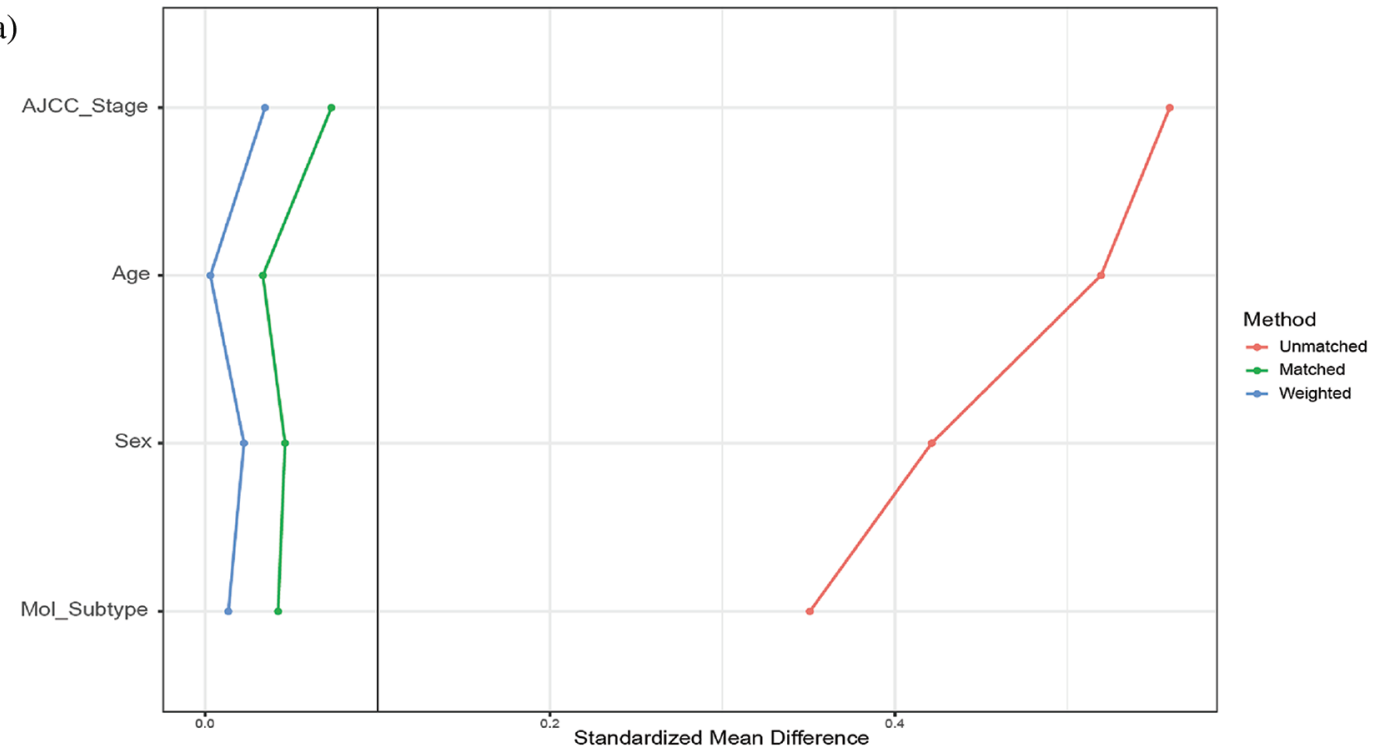

(b)
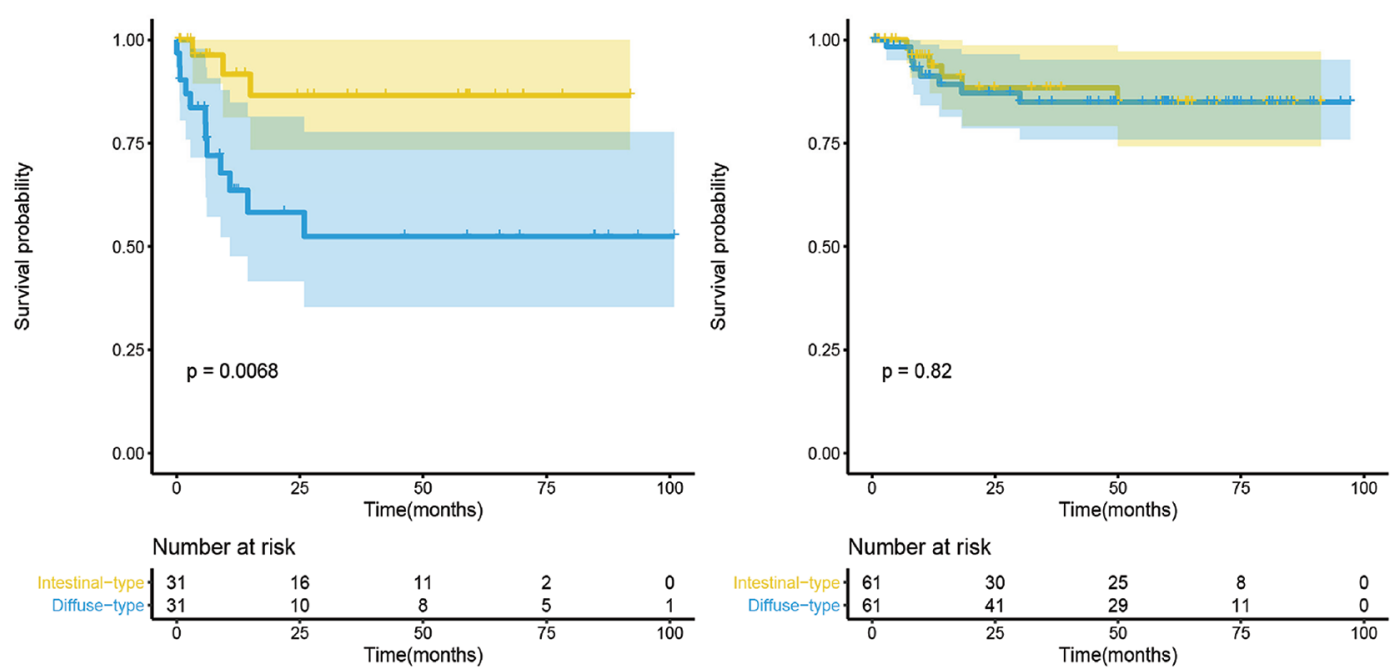

(c)

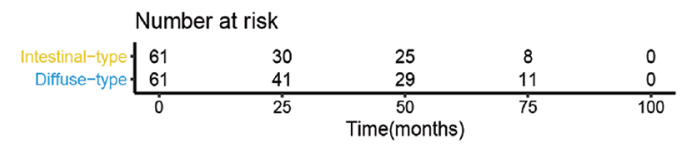

IIntestinal-type $=$ Diffuse-type

\pm Intestinal-type $=$ Diffuse-type
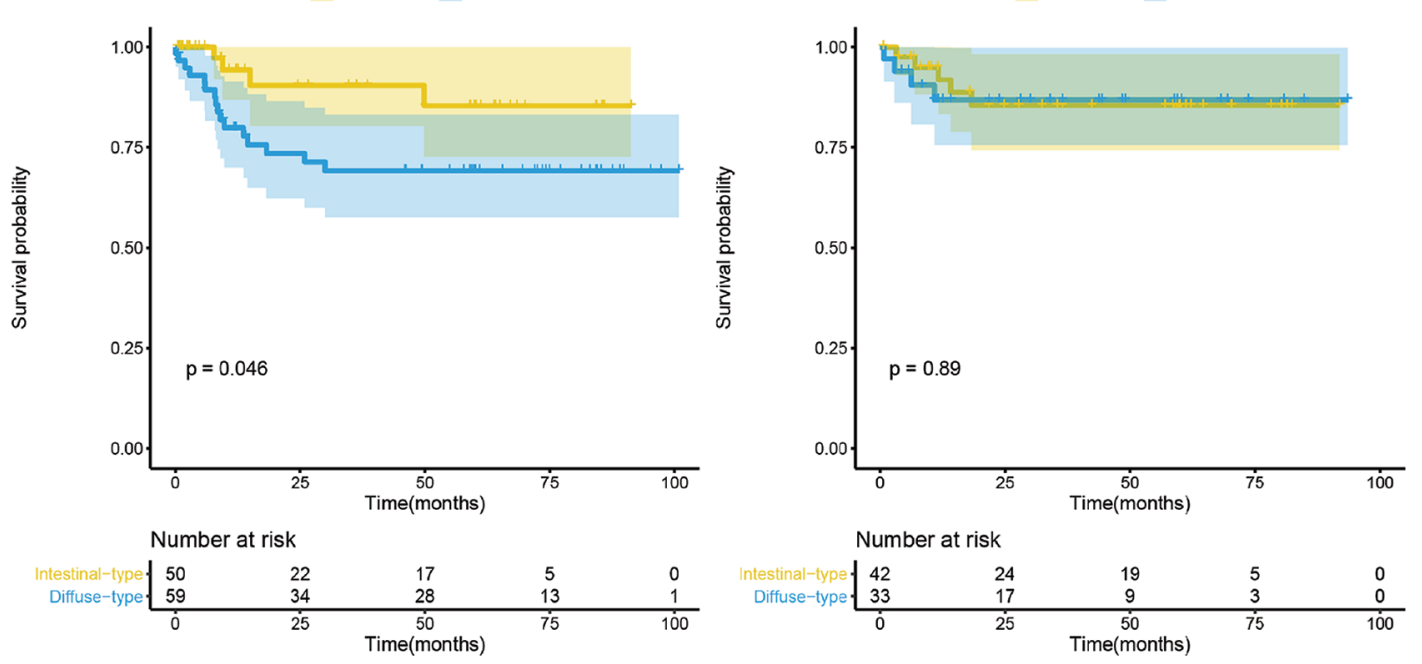

FIGURE 4. (continued) 

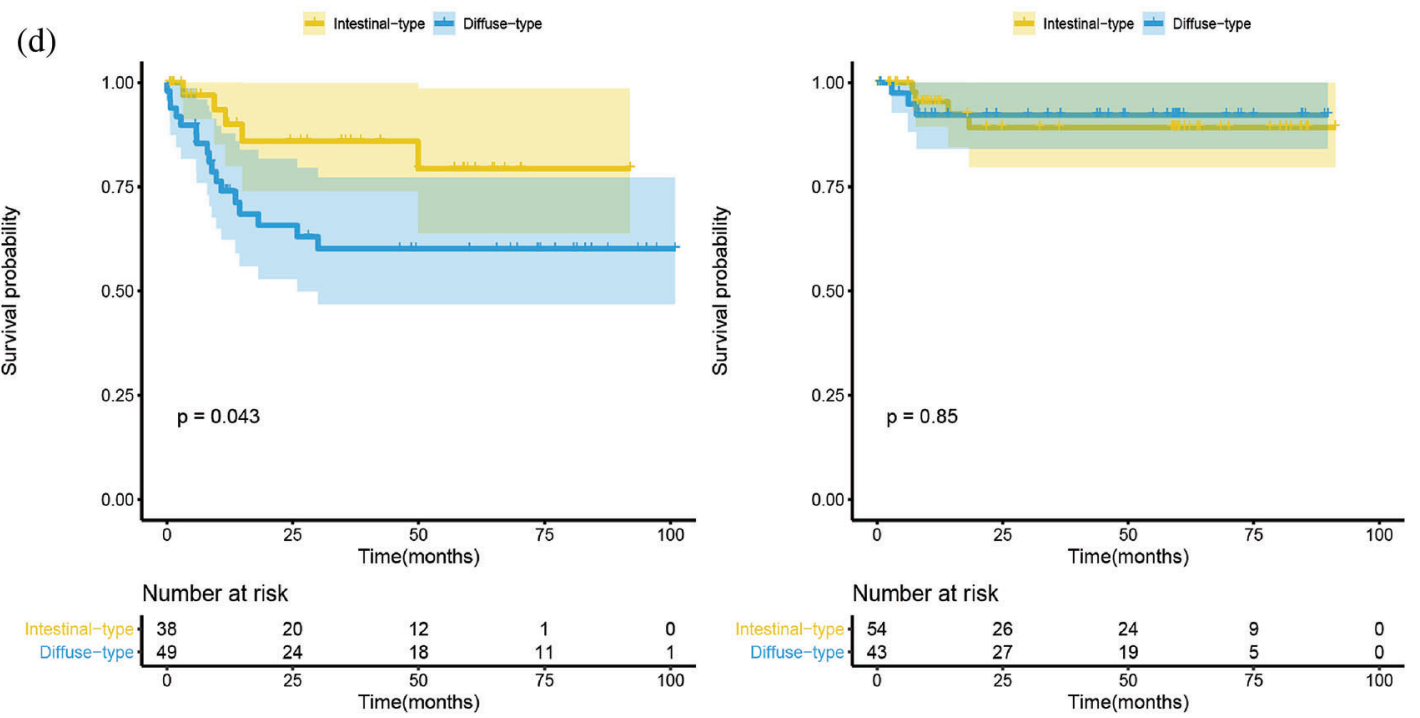

FIGURE 4. (a) Results of propensity score matching. (b-d) Kaplan-Meier survival curves of PRKAA2 (b), HAND2-AS1 (c), and VLDLR (d) between high (left side) and low (right side) expression levels and 1-year psDFS measured by STEPP in diffuse-type and intestinal-type GC patients after propensity score matching $P<0.05$ was considered statistically significant.

TABLE 2

Baseline characteristics before and after propensity score matching (PSM)

\begin{tabular}{|c|c|c|c|c|c|c|}
\hline \multirow[b]{2}{*}{ Variables } & \multicolumn{3}{|c|}{ Before matching } & \multicolumn{3}{|c|}{ After matching } \\
\hline & $\begin{array}{l}\text { Diffuse-type } \\
(\mathrm{N}=135)\end{array}$ & $\begin{array}{l}\text { Intestinal-type } \\
(\mathrm{N}=145)\end{array}$ & $P$-value & $\begin{array}{l}\text { Diffuse-type } \\
(\mathrm{N}=92)\end{array}$ & $\begin{array}{l}\text { Intestinal-type } \\
(\mathrm{N}=92)\end{array}$ & $P$-value \\
\hline Sex & & & $<0.01$ & & & 0.88 \\
\hline Female & $60(44.44 \%)$ & $36(24.83 \%)$ & & $31(33.7 \%)$ & $29(31.52 \%)$ & \\
\hline Male & $75(55.56 \%)$ & $109(75.17 \%)$ & & $61(66.3 \%)$ & $63(68.48 \%)$ & \\
\hline Age & & & $<0.01$ & & & 1 \\
\hline$\leq 63$ & $81(60 \%)$ & $63(43.45 \%)$ & & $45(48.91 \%)$ & $46(50 \%)$ & \\
\hline$>63$ & $54(40 \%)$ & $82(56.55 \%)$ & & 47 (51.09\%) & $46(50 \%)$ & \\
\hline T Stage & & & $<0.01$ & & & 0.55 \\
\hline 2 & $65(48.15 \%)$ & $109(75.17 \%)$ & & $53(57.61 \%)$ & $60(65.22 \%)$ & \\
\hline 3 & $60(44.44 \%)$ & $25(17.24 \%)$ & & $34(36.96 \%)$ & $21(22.83 \%)$ & \\
\hline 4 & $10(7.41 \%)$ & $11(7.59 \%)$ & & $5(5.43 \%)$ & $11(11.96 \%)$ & \\
\hline N Stage & & & $<0.01$ & & & 0.90 \\
\hline 0 & $8(5.93 \%)$ & $28(19.31 \%)$ & & $6(6.52 \%)$ & $10(10.87 \%)$ & \\
\hline 1 & $54(40 \%)$ & $69(47.59 \%)$ & & $46(50 \%)$ & $42(45.65 \%)$ & \\
\hline 2 & $41(30.37 \%)$ & $31(21.38 \%)$ & & $27(29.35 \%)$ & $24(26.09 \%)$ & \\
\hline 3 & $32(23.7 \%)$ & $17(11.72 \%)$ & & $13(14.13 \%)$ & $16(17.39 \%)$ & \\
\hline M Stage & & & $<0.01$ & & & 0.16 \\
\hline 0 & $115(85.19 \%)$ & $139(95.86 \%)$ & & $82(89.13 \%)$ & $88(95.65 \%)$ & \\
\hline 1 & $20(14.81 \%)$ & $6(4.14 \%)$ & & $10(10.87 \%)$ & $4(4.35 \%)$ & \\
\hline pStage & & & $<0.01$ & & & 0.62 \\
\hline I & $5(3.7 \%)$ & $23(15.86 \%)$ & & $5(5.43 \%)$ & $6(6.52 \%)$ & \\
\hline II & $35(25.93 \%)$ & $56(38.62 \%)$ & & $33(35.87 \%)$ & $32(34.78 \%)$ & \\
\hline III & $49(36.3 \%)$ & $38(26.21 \%)$ & & 35 (38.04\%) & $28(30.43 \%)$ & \\
\hline IV & $46(34.07 \%)$ & $28(19.31 \%)$ & & $19(20.65 \%)$ & $26(28.26 \%)$ & \\
\hline Status & & & $<0.01$ & & & 0.88 \\
\hline Alive & $56(41.48 \%)$ & $85(58.62 \%)$ & & $50(54.35 \%)$ & $52(56.52 \%)$ & \\
\hline Dead & $79(58.52 \%)$ & $60(41.38 \%)$ & & $42(45.65 \%)$ & $40(43.48 \%)$ & \\
\hline
\end{tabular}



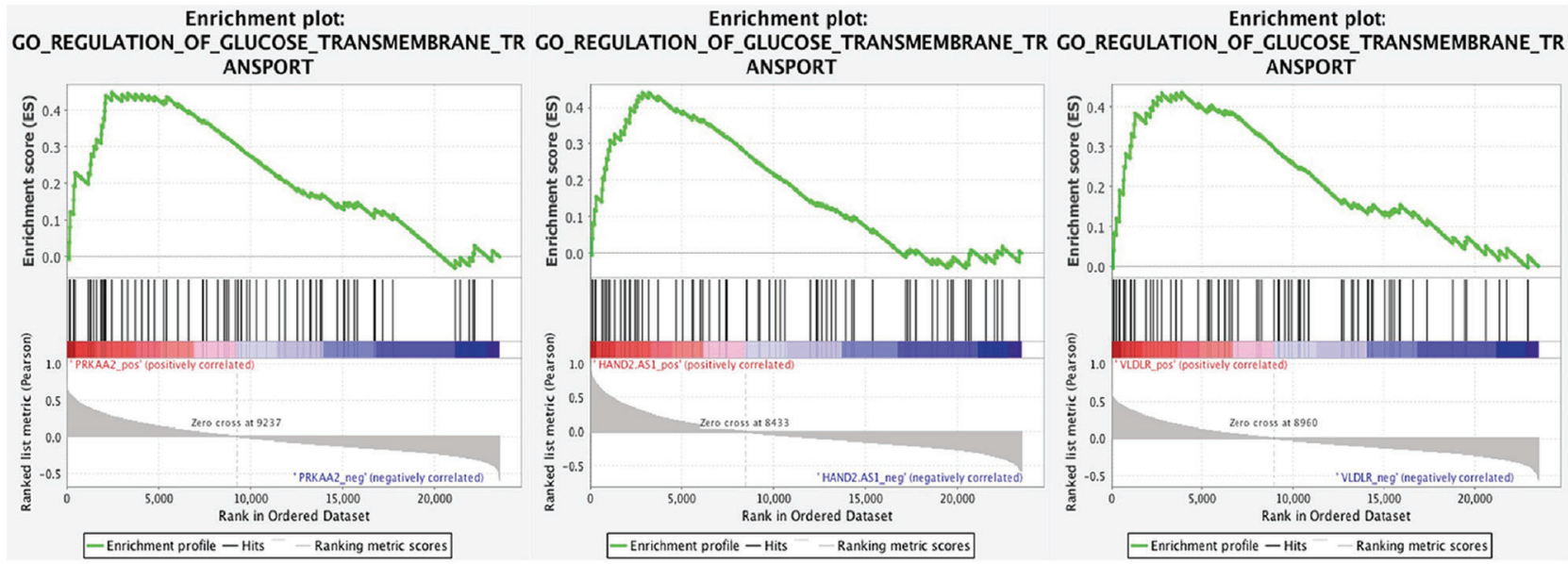

(a)
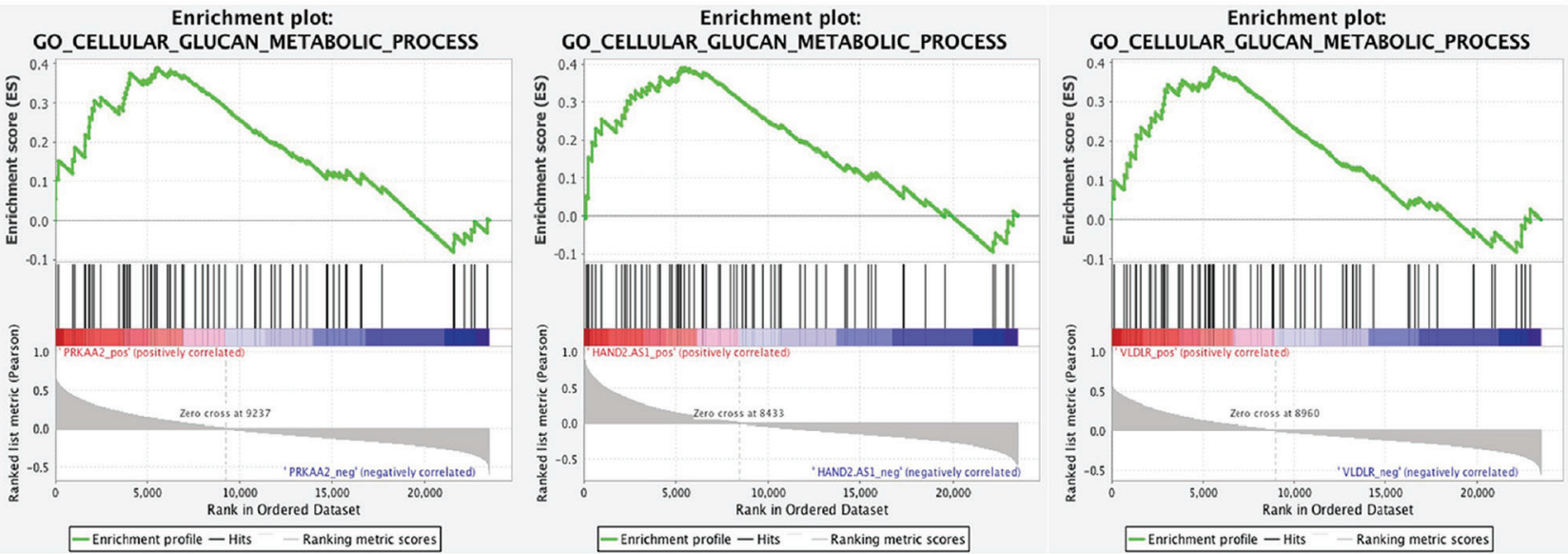

(b)
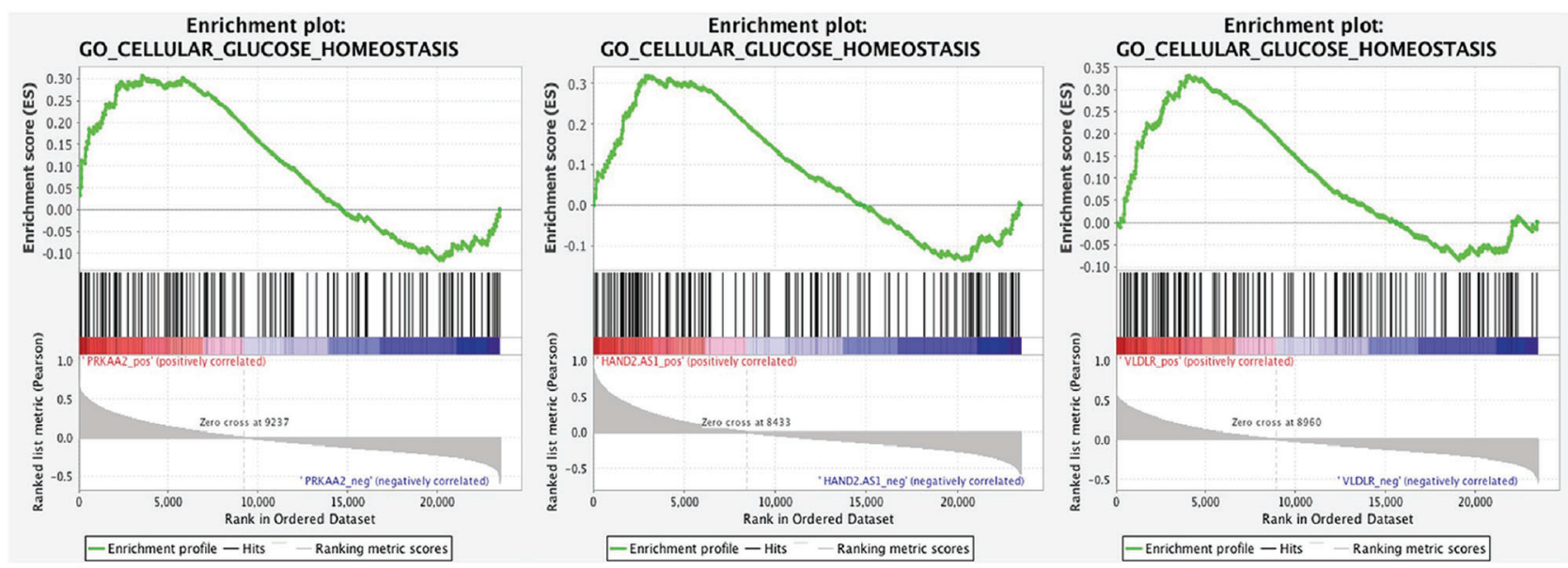

(c)

FIGURE 5. (continued) 

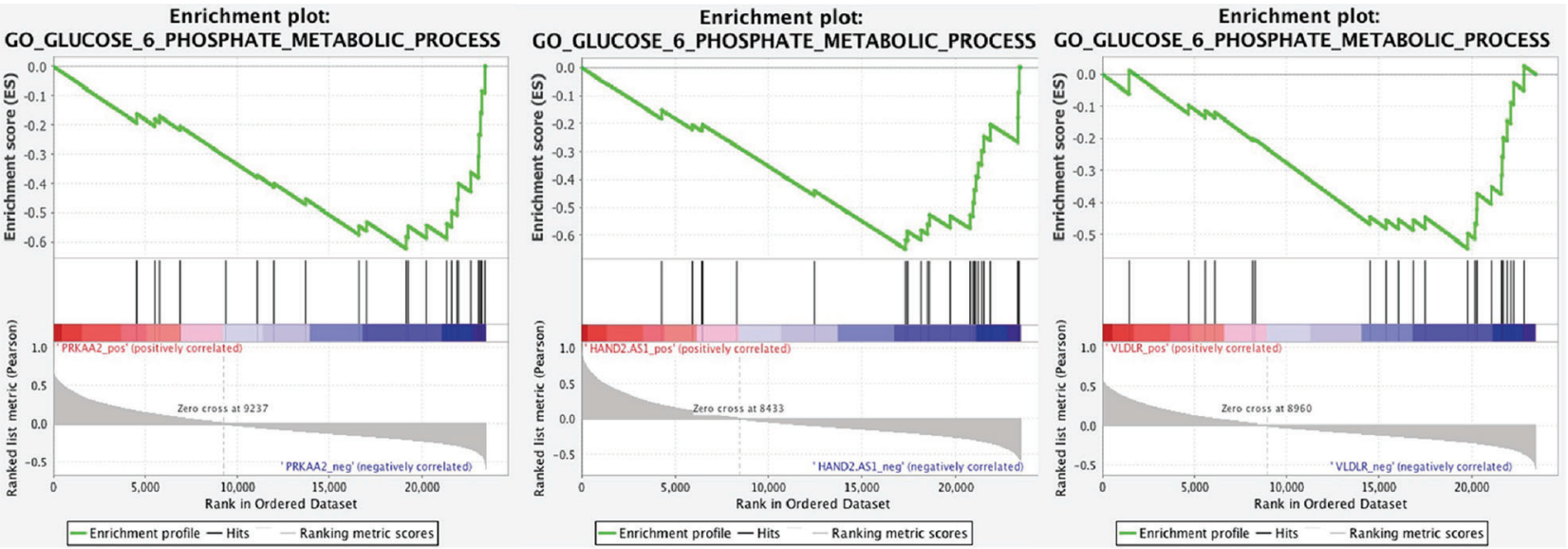

(d)
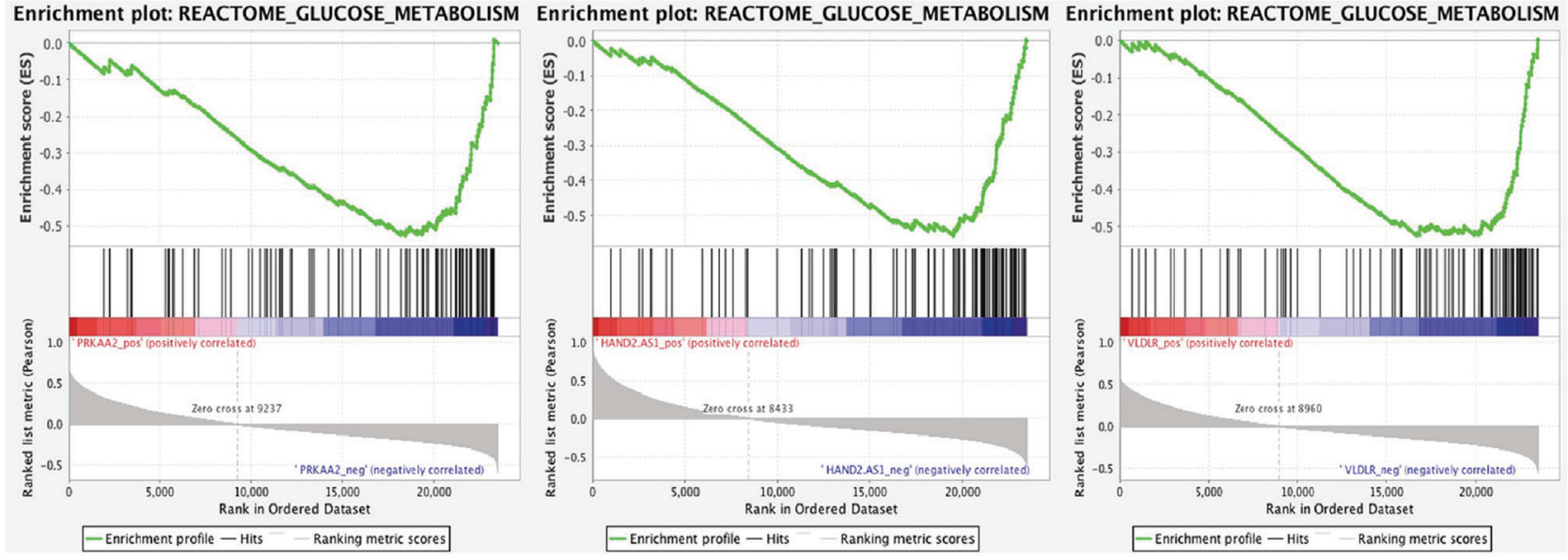

(e)

FIGURE 5. PRKAA2, HAND2-AS1, and VLDLR were enriched in glucose metabolism-related pathways in GC.

(A-C) The enrichment plot for the association of gene sets positively correlated with PRKAA2, HAND2-AS1, and VLDLR in the GSE62254 dataset. (D, E) The enrichment plot of the gene set in GSE62254 was negatively correlated with PRKAA2, HAND2-AS1, and VLDLR correlation. The significance threshold was set to $P<0.05$ and FDR $<0.25$.

\section{Conclusion}

Three genes, namely HAND2-AS1, PRKAA2, and VLDLR, were identified as potentially promoting the early development of peritoneal metastasis in diffuse-type GC.

Acknowledgement: The authors would like to acknowledge the Key Laboratory of Precision Diagnosis and Treatment of Gastrointestinal Tumors, Ministry of Education (China Medical University, Shenyang, China) for providing the space and equipment for conducting the experiments.

Availability of Data and Materials: The datasets analyzed during the current study are available from the corresponding author on reasonable request.

Author Contributions: Conceptualization, Zhi $\mathrm{Li}$ and Xiujuan Qu; Formal analysis, Hui Qu, Ruichuan Shi and Zhi Li; Funding acquisition, Xiujuan Qu; Investigation, Hui $\mathrm{Qu}$ and Ruichuan Shi; Methodology, Hui Qu, Ruichuan Shi, Bowen Yang, and Zhi Li; Resources, Xi Chen, Yujia Song, Lingzi He, Yiting Sun, Yujing Yang; Supervision, Zhi Li and Xiujuan Qu; Writing-original draft, Hui Qu and Ruichuan Shi; Writing-review \& editing, Zhi Li and Xiujuan Qu.
Funding Statement: This research was approved by National Natural Science Foundation of China (No. 81972331); National Science and Technology Major Project of the Ministry of Science and Technology of China (No. 2017ZX09304025).

Conflicts of Interest: The authors declare that they have no conflicts of interest to report regarding the present study.

\section{References}

Almeida R, Almeida J, Shoshkes M, Mendes N, Mesquita P, Silva E, van Seuningen I, Reis CA, Santos-Silva F, David L (2005). OCT-1 is over-expressed in intestinal metaplasia and intestinal gastric carcinomas and binds to, but does not transactivate, CDX2 in gastric cells. Journal of Pathology 207: 396-401. DOI 10.1002/ path.1861.

Arnold M, Ferlay J, Van Berge Henegouwen MI, Soerjomataram I (2020). Global burden of oesophageal and gastric cancer by histology and subsite in 2018. Gut 69: 1564-1571. DOI 10.1136/gutjnl-2020-321600.

Asano N, Imatani A, Watanabe T, Fushiya J, Kondo Y, Jin X, Ara N, Uno K, Iijima K, Koike T, Strober W, Shimosegawa T (2016). $\mathrm{Cdx} 2$ expression and intestinal metaplasia induced by H. pylori infection of gastric cells is regulated by 
NOD1-mediated innate immune responses. Cancer Research 76: 1135-1145. DOI 10.1158/0008-5472.CAN-15-2272.

Baker SG, Bonetti M (2016). Evaluating markers for guiding treatment. Journal of the National Cancer Institute 108: djw101. DOI 10.1093/jnci/djw101.

Bao B, Zheng C, Yang B, Jin Y, Hou K, Li Z, Zheng X, Yu S, Zhang X, Fan Y, Qu X, Liu Y, Che X (2019). Identification of subtypespecific three-gene signature for prognostic prediction in diffuse type gastric cancer. Frontiers in Oncology 9: 1243. DOI 10.3389/fonc.2019.01243.

Casadaban L, Rauscher G, Aklilu M, Villenes D, Freels S, Maker AV (2016). Adjuvant chemotherapy is associated with improved survival in patients with stage II colon cancer. Cancer 122: 3277-3287. DOI 10.1002/cncr.30181.

Cristescu R, Lee J, Nebozhyn M, Kim KM, Ting JC, Wong SS, Liu J, Yue YG, Wang J, Yu K, Ye XS, Do IG, Liu S, Gong L, Fu J, Jin JG, Choi MG, Sohn TS, Lee JH, Bae JM, Kim ST, Park SH, Sohn I, Jung SH, Tan P, Chen R, Hardwick J, Kang WK, Ayers M, Hongyue D, Reinhard C, Loboda A, Kim S, Aggarwal A (2015). Molecular analysis of gastric cancer identifies subtypes associated with distinct clinical outcomes. Nature Medicine 21: 449-456. DOI 10.1038/nm.3850.

Chang HR, Nam S, Kook MC, Kim KT, Liu X, Yao H, Jung HR, Lemos R, Seo HH, Jr, Park HS, Gim Y, Hong D, Huh I, Kim YW, Tan D, Liu CG, Powis G, Park T, Liang H, Kim YH (2016). HNF4a is a therapeutic target that links AMPK to WNT signalling in early-stage gastric cancer. Gut $\mathbf{6 5}$ : 19-32. DOI 10.1136/gutjnl-2014-307918.

Chen S, Xu X, Lu S, Hu B (2019). Long non-coding RNA HAND2-AS1 targets glucose metabolism and inhibits cancer cell proliferation in osteosarcoma. Oncology Letters 18: 1323-1329.

D'Agostino RB, Jr (1998). Propensity score methods for bias reduction in the comparison of a treatment to a nonrandomized control group. Statistics in Medicine 17: 22652281. DOI 10.1002/(SICI)1097-0258(19981015)17:19<2265:: AID-SIM918>3.0.CO;2-B.

Dong D, Tang L, Li ZY, Fang MJ, Gao JB, Shan XH, Ying XJ, Sun YS, Fu J, Wang XX, Li LM, Li ZH, Zhang DF, Zhang Y, Li ZM, Shan F, Bu ZD, Tian J, Ji JF (2019). Development and validation of an individualized nomogram to identify occult peritoneal metastasis in patients with advanced gastric cancer. Annals of Oncology 30: 431-438. DOI 10.1093/ annonc/mdz001.

Gautier L, Cope L, Bolstad BM, Irizarry RA (2004). Affy-Analysis of Affymetrix GeneChip data at the probe level. Bioinformatics 20: 307-315. DOI 10.1093/bioinformatics/btg405.

Gokulnath P, De Cristofaro T, Manipur I, Di Palma T, Soriano AA, Guarracino MR, Zannini M (2020). Long non-coding RNA HAND2-AS1 acts as a tumor suppressor in high-grade serous ovarian carcinoma. International Journal of Molecular Sciences 21: 4059. DOI 10.3390/ijms21114059.

Honma Y, Terauchi T, Tateishi U, Kano D, Nagashima K, Shoji H, Iwasa S, Takashima A, Kato K, Hamaguchi T, Boku N, Shimada Y, Yamada Y (2018). Imaging peritoneal metastasis of gastric cancer with (18)F-fluorothymidine positron emission tomography/computed tomography: a proof-of-concept study. British Journal of Radiology 91: 20180259. DOI 10.1259/bjr.20180259.

Imaoka $\mathrm{H}$, Toiyama $\mathrm{Y}$, Okigami M, Yasuda $\mathrm{H}$, Saigusa $\mathrm{S}$, Ohi $\mathrm{M}$, Tanaka K, Inoue Y, Mohri Y, Kusunoki M (2016). Circulating microRNA-203 predicts metastases, early recurrence, and poor prognosis in human gastric cancer. Gastric Cancer 19: 744-753. DOI 10.1007/s10120-015-0521-0.
Jeon CH, Kim IH, Chae HD (2014). Prognostic value of genetic detection using CEA and MAGE in peritoneal washes with gastric carcinoma after curative resection: Result of a 3-year follow-up. Medicine 93: e83. DOI 10.1097/MD.0000000000000083.

Kawamura T, Kusakabe T, Sugino T, Watanabe K, Fukuda T, Nashimoto A, Honma K, Suzuki T (2001). Expression of glucose transporter-1 in human gastric carcinoma: Association with tumor aggressiveness, metastasis, and patient survival. Cancer 92: 634-641. DOI 10.1002/10970142(20010801)92:3<634::AID-CNCR1364> 3.0.CO;2-X.

Kensler KH, Regan MM, Heng YJ, Baker GM, Pyle ME, Schnitt SJ, Hazra A, Kammler R, Thürlimann B, Colleoni M, Viale G, Brown M, Tamimi RM (2019). Prognostic and predictive value of androgen receptor expression in postmenopausal women with estrogen receptor-positive breast cancer: results from the Breast International Group Trial 1-98. Breast Cancer Research 21: 30. DOI 10.1186/s13058-019-1118-z.

Lauren P (1965). The two histological main types of gastric carcinoma: Diffuse and so-called intestinal-type carcinoma. An attempt at a histo-clinical classification. Acta Pathologica Microbiologica Scandinavica 64: 31-49. DOI 10.1111/apm.1965.64.1.31.

Lazăr D, Tăban S, Ardeleanu C, Dema A, Sporea I, Cornianu M, Lazăr E, Vernic C (2008). The immunohistochemical expression of E-cadherin in gastric cancer; correlations with clinicopathological factors and patients' survival. Romanian Journal of Morphology and Embryology 49: 459-467.

Lee JH, Chang KK, Yoon C, Tang LH, Strong VE, Yoon SS (2018). Lauren histologic type is the most important factor associated with pattern of recurrence following resection of gastric adenocarcinoma. Annals of Surgery 267: 105-113. DOI 10.1097/SLA.0000000000002040.

Li H, Wang J, Xu H, Xing R, Pan Y, Li W, Cui J, Zhang H, Lu Y (2013). Decreased fructose-1,6-bisphosphatase-2 expression promotes glycolysis and growth in gastric cancer cells. Molecular Cancer 12: 110. DOI 10.1186/1476-4598-12-110.

Li W, Wong CC, Zhang X, Kang W, Nakatsu G, Zhao Q, Chen H, Go MYY, Chiu PWY, Wang X, Ji J, Li X, Cai Z, Ng EKW, Yu J (2018). CAB39L elicited an anti-Warburg effect via a LKB1-AMPK-PGC1 $\alpha$ axis to inhibit gastric tumorigenesis. Oncogene 37: 6383-6398. DOI 10.1038/s41388-018-0402-1.

Li Y, Ma D, Li T, Yin Y (2020a). Identification of functional long noncoding RNAs in gastric cancer by bioinformatics analysis. International Journal of Experimental Pathology 101: 96-105. DOI 10.1111/iep.12350.

Li Z, Li AD, Xu L, Bai DW, Hou KZ, Zheng HC, Qu XJ, Liu YP (2016a). SPARC expression in gastric cancer predicts poor prognosis: Results from a clinical cohort, pooled analysis and GSEA assay. Oncotarget 7: 70211-70222. DOI 10.18632/ oncotarget.12191.

Li Z, Wang JW, Wang WZ, Zhi XF, Zhang Q, Li BW, Wang LJ, Xie KL, Tao JQ, Tang J, Wei S, Zhu Y, Xu H, Zhang DC, Yang L, $\mathrm{Xu}$ ZK (2016b). Natriuretic peptide receptor A inhibition suppresses gastric cancer development through reactive oxygen species-mediated G2/M cell cycle arrest and cell death. Free Radical Biology and Medicine 99: 593-607. DOI 10.1016/j.freeradbiomed.2016.08.019.

Li ZY, Tang L, Li ZM, Li YL, Fu J, Zhang Y, Li XT, Ying XJ, Ji JF (2020b). Four-point computed tomography scores for evaluation of occult peritoneal metastasis in patients with gastric cancer: A region-to-region comparison with staging laparoscopy. Annals of Surgical Oncology 27: 1103-1109. DOI 10.1245/s10434-019-07812-y. 
Liu W, Zhong S, Chen J, Yu Y (2012). HER-2/neu overexpression is an independent prognostic factor for intestinal-type and early-stage gastric cancer patients. Journal of Clinical Gastroenterology 46: e31-e37. DOI 10.1097/MCG.0b013e31823457ea.

Liu YC, Shen CY, Wu HS, Hsieh TY, Chan DC, Chen CJ, Yu JC, Yu CP, Harn HJ, Chen PJ, Hsieh CB, Chen TW, Hsu HM (2006). Mechanisms inactivating the gene for E-cadherin in sporadic gastric carcinomas. World Journal of Gastroenterology 12: 2168-2173. DOI 10.3748/wjg.v12.i14.2168.

Machado JC, Oliveira C, Carvalho R, Soares P, Berx G, Caldas C, Seruca R, Carneiro F, Sobrinho-Simöes M (2001). Ecadherin gene $(\mathrm{CDH} 1)$ promoter methylation as the second hit in sporadic diffuse gastric carcinoma. Oncogene 20: 1525-1528. DOI 10.1038/sj.onc.1204234.

Nishina T, Boku N, Gotoh M, Shimada Y, Hamamoto Y, Yasui H, Yamaguchi K, Kawai $H$, Nakayama $\mathrm{N}$, Amagai $\mathrm{K}$, Mizusawa J, Nakamura K, Shirao K, Ohtsu A (2016). Randomized phase II study of second-line chemotherapy with the best available 5-fluorouracil regimen versus weekly administration of paclitaxel in far advanced gastric cancer with severe peritoneal metastases refractory to 5fluorouracil-containing regimens (JCOG0407). Gastric Cancer 19: 902-910. DOI 10.1007/s10120-015-0542-8.

Oganesian A, Armstrong LC, Migliorini MM, Strickland DK, Bornstein P (2008). Thrombospondins use the VLDL receptor and a nonapoptotic pathway to inhibit cell division in microvascular endothelial cells. Molecular Biology of the Cell 19: 563-571. DOI 10.1091/mbc.e07-07-0649.

Perrot-Applanat M, Vacher S, Pimpie C, Chemlali W, Derieux S, Pocard M, Bieche I (2019). Differential gene expression in growth factors, epithelial mesenchymal transition and chemotaxis in the diffuse type compared with the intestinal type of gastric cancer. Oncology Letters 18: 674-686.

Pilotto S, Sperduti I, Leuzzi G, Chiappetta M, Mucilli F, Ratto GB, Lococo F, Filosso PL, Spaggiari L, Novello S, Milella M, Santo A, Scarpa A, Infante M, Tortora G, Facciolo F, Bria E (2018). Prognostic model for resected squamous cell lung cancer: external multicenter validation and propensity score analysis exploring the impact of adjuvant and neoadjuvant treatment. Journal of Thoracic Oncology 13: 568-575. DOI 10.1016/j.jtho.2017.12.003.

Rao SV, Solum G, Niederdorfer B, Nørsett KG, Bjørkøy G, Thommesen L (2017). Gastrin activates autophagy and increases migration and survival of gastric adenocarcinoma cells. BMC Cancer 17: 68. DOI 10.1186/s12885-017-3055-5.

Rawicz-Pruszyński K, Ciseł B, Mlak R, Mielko J, Skórzewska M, Kwietniewska M, Pikuła A, Gęca K, Sędłak K, Kurylcio A, Polkowski WP (2019). The role of the lymph node ratio in advanced gastric cancer after neoadjuvant chemotherapy. Cancers 11: 1914. DOI 10.3390/cancers11121914.

Rebustini IT, Hayashi T, Reynolds AD, Dillard ML, Carpenter EM, Hoffman MP (2012). miR-200c regulates FGFR-dependent epithelial proliferation via Vldlr during submandibular gland branching morphogenesis. Development 139: 191202. DOI 10.1242/dev.070151.

Riihimäki M, Hemminki A, Sundquist K, Sundquist J, Hemminki K (2016). Metastatic spread in patients with gastric cancer. Oncotarget 7: 52307-52316. DOI 10.18632/oncotarget.10740.

Sawaki K, Kanda M, Ito S, Mochizuki Y, Teramoto H, Ishigure K, Murai T, Asada T, Ishiyama A, Matsushita H, Tanaka C, Kobayashi D, Fujiwara M, Murotani K, Kodera Y (2020). Survival times are similar among patients with peritoneal, hematogenous, and nodal recurrences after curative resections for gastric cancer. Cancer Medicine 9: 5392 5399. DOI 10.1002/cam4.3208.

Sawhney S, Wilson SR (2017). Can ultrasound with contrast enhancement replace nonenhanced computed tomography scans in patients with contraindication to computed tomography contrast agents? Ultrasound Quarterly 33: 125-132. DOI 10.1097/RUQ.0000000000000271.

Schirren R, Novotny A, Friess H, Reim D (2020). Histopathologic response is a positive predictor of overall survival in patients undergoing neoadjuvant/perioperative chemotherapy for locally advanced gastric or gastroesophageal junction cancers-analysis from a large single center cohort in germany. Cancers 12: 2244. DOI 10.3390/cancers12082244.

Shi S, Tan Q, Feng F, Huang H, Liang J, Cao D, Wang Z (2020). Identification of core genes in the progression of endometrial cancer and cancer cell-derived exosomes by an integrative analysis. Scientific Reports 10: 9862. DOI 10.1038/ s41598-020-66872-3.

Stănculescu D, Mărgăritescu C, Stepan A, Mitruţ AO (2011). Ecadherin in gastric carcinomas related to histological prognostic parameters. Romanian Journal of Morphology and Embryology 52: 1107-1112.

Varet H, Brillet-Guéguen L, Coppée JY, Dillies MA (2016). SARTools: A DESeq2- and EdgeR-based R pipeline for comprehensive differential analysis of RNA-Seq data. PLoS One 11: e0157022. DOI 10.1371/journal.pone.0157022.

Wang K, Li E, Busuttil RA, Kong JC, Pattison S, Sung JJY, Yu J, ElOmar EM, Simpson JA, Boussioutas A (2020). A cohort study and meta-analysis of the evidence for consideration of Lauren subtype when prescribing adjuvant or palliative chemotherapy for gastric cancer. Therapeutic Advances in Medical Oncology 12: 1758835920930359.

Xu Z, Lv H, Wang Y, Hu C, Chen S, Du Y, Shi C, Cheng X (2020). HAND2-AS1 inhibits gastric adenocarcinoma cells proliferation and aerobic glycolysis via miRNAs sponge. Cancer Management and Research 12: 3053-3068.

Yip WK, Bonetti M, Cole BF, Barcella W, Wang XV, Lazar A, Gelber RD (2016). Subpopulation treatment effect pattern plot (STEPP) analysis for continuous, binary, and count outcomes. Clinical Trials 13: 382-390. DOI 10.1177/1740774516643297.

Yu L, Li H, Li Z, Jia J, Wu Z, Wang M, Li F, Feng Z, Xia H, Gao G (2020). Long non-coding RNA HAND2-AS1 inhibits growth and migration of gastric cancer cells through regulating the miR-590-3p/KCNT2 axis. Onco Targets \& Therapy 13: 3187-3196.

Yu Z, Li Z, Wang C, Pan T, Chang X, Wang X, Zhou Q, Wu X, Li J, Zhang J, Liu B, Zhu Z, Su L (2019). Oncostatin M receptor, positively regulated by $\mathrm{SP} 1$, promotes gastric cancer growth and metastasis upon treatment with Oncostatin M. Gastric Cancer 22: 955-966. DOI 10.1007/s10120-019-00934-y.

Zenimaru Y, Takahashi S, Takahashi M, Yamada K, Iwasaki T, Hattori H, Imagawa M, Ueno M, Suzuki J, Miyamori I (2008). Glucose deprivation accelerates VLDL receptormediated TG-rich lipoprotein uptake by AMPK activation in skeletal muscle cells. Biochemical and Biophysical Research Communications 368: 716-722. DOI 10.1016/j. bbrc.2008.01.154.

Zhang H, Schaefer A, Wang Y, Hodge RG, Blake DR, Diehl JN, Papageorge AG, Stachler MD, Liao J, Zhou J, Wu Z, Akarca FG, de Klerk LK, Derks S, Pierobon M, Hoadley KA, Wang TC, Church G, Wong KK, Petricoin EF, Cox AD, Lowy DR, Der CJ, Bass AJ (2020a). Gain-of-function mutations promote focal adhesion kinase activation and 
dependency in diffuse gastric cancer. Cancer Discovery 10: 288-305. DOI 10.1158/2159-8290.CD-19-0811.

Zhang Y, Zhao J, Yu H, Li P, Liang W, Liu Z, Lee GB, Liu L, Li WJ, Wang Z (2020b). Detection and isolation of free cancer cells from ascites and peritoneal lavages using optically induced electrokinetics (OEK). Science Advances 6: eaba9628. DOI 10.1126/sciadv.aba9628.

Zhao J, Qin R, Chen H, Yang Y, Qin W, Han J, Wang X, Ren S, Sun Y, $\mathrm{Gu} J$ (2020). A nomogram based on glycomic biomarkers in serum and clinicopathological characteristics for evaluating the risk of peritoneal metastasis in gastric cancer. Clinical Proteomics 17: 34. DOI 10.1186/s12014-020-09297-4.

Zhu YF, Dong M (2018). Expression of TUSC3 and its prognostic significance in colorectal cancer. Pathology-Research and Practice 214: 1497-1503. DOI 10.1016/j.prp.2018.07.004.

Zou J, Li Z, Deng H, Hao J, Ding R, Zhao M (2019). TMEM213 as a novel prognostic and predictive biomarker for patients with lung adenocarcinoma after curative resection: A study based on bioinformatics analysis. Journal of Thoracic Disease 11: 3399-3410. DOI 10.21037/jtd.2019.08.01.

\section{Supplementary Materials}

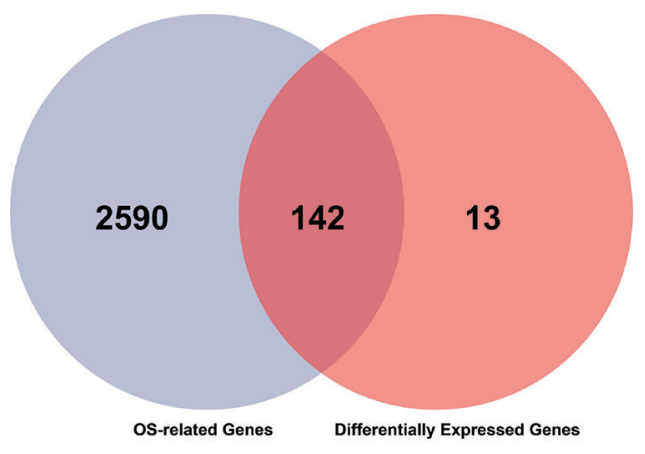

SUPPLEMENTARY FIGURE S1. Venn diagram of 142 overlapping genes.

\section{SUPPLEMENTARY TABLE S1}

$r_{1}$ and $r_{2}$ values selected for STEPP analysis

\begin{tabular}{|c|c|c|c|c|c|c|}
\hline Gene & r1 & $\mathbf{r 2}$ & Subpopulations & $\begin{array}{l}\text { The supremum statistic } \\
\text { in the relative scale }\end{array}$ & $\begin{array}{l}\text { The chisq statistics in } \\
\text { the absolute scale }\end{array}$ & The supremum statistic \\
\hline HAND2.AS1 & 7 & 70 & 5 & 0.1284 & 0.0132 & 0.0932 \\
\hline HAND2.AS1 & 21 & 70 & 6 & 0.5828 & 0.028 & 0.4312 \\
\hline HAND2.AS1 & 35 & 70 & 7 & 0.3064 & 0.0556 & 0.4596 \\
\hline HAND2.AS1 & 49 & 70 & 11 & 0.1748 & 0.0104 & 0.268 \\
\hline HAND2.AS1 & 63 & 70 & 31 & 0.1616 & 0.1892 & 0.3212 \\
\hline HAND2.AS1 & 12 & 120 & 3 & 0.1008 & 0.0092 & 0.1268 \\
\hline HAND2.AS1 & 36 & 120 & 3 & 0.0812 & 0.0796 & 0.0512 \\
\hline $\mathrm{HAND}_{2 . \mathrm{AS} 1^{\dagger}}$ & 60 & 120 & 4 & 0.0872 & 0.1652 & 0.1516 \\
\hline HAND2.AS1 & 84 & 120 & 6 & 0.0288 & 0.1284 & 0.1128 \\
\hline HAND2.AS1 & 108 & 120 & 15 & 0.044 & 0.2444 & 0.1376 \\
\hline HAND2.AS1 & 17 & 170 & 2 & 0.0228 & 0.0292 & 0.014 \\
\hline HAND2.AS1 & 51 & 170 & 2 & 0.0272 & 0.0312 & 0.0152 \\
\hline HAND2.AS1 & 85 & 170 & 3 & 0.0348 & 0.0064 & 0.0236 \\
\hline HAND2.AS1 & 119 & 170 & 4 & 0.0396 & 0.0572 & 0.0324 \\
\hline HAND2.AS1 & 153 & 170 & 8 & 0.1024 & 0.0168 & 0.0484 \\
\hline PRKAA2 & 7 & 70 & 5 & 0.1168 & 0.0208 & 0.0372 \\
\hline PRKAA2 & 21 & 70 & 6 & 0.0624 & 0.01 & 0.0016 \\
\hline PRKAA2 & 35 & 70 & 7 & 0.1572 & 0.004 & 0.0016 \\
\hline PRKAA2 & 49 & 70 & 11 & 0.0364 & 0.0048 & 0.0028 \\
\hline PRKAA2 & 63 & 70 & 31 & 0.0932 & 0.0236 & 0.008 \\
\hline
\end{tabular}




\begin{tabular}{|c|c|c|c|c|c|c|}
\hline Gene & r1 & r2 & Subpopulations & $\begin{array}{l}\text { The supremum statistic } \\
\text { in the relative scale }\end{array}$ & $\begin{array}{l}\text { The chisq statistics in } \\
\text { the absolute scale }\end{array}$ & The supremum statistic \\
\hline PRKAA2 & 12 & 120 & 3 & 0.0352 & $4.00 \mathrm{E}-04$ & $8.00 \mathrm{E}-04$ \\
\hline PRKAA2 & 36 & 120 & 3 & 0.03 & 0.0092 & 0.0188 \\
\hline${\text { PRKAA }{ }^{\dagger}}^{\dagger}$ & 60 & 120 & 4 & 0.024 & 0 & 0.0068 \\
\hline PRKAA2 & 84 & 120 & 6 & 0.0148 & $4.00 \mathrm{E}-04$ & 0.0072 \\
\hline PRKAA2 & 108 & 120 & 15 & 0.0236 & 0.0016 & 0.0536 \\
\hline PRKAA2 & 17 & 170 & 2 & 0.0012 & 0.0224 & 0.0064 \\
\hline PRKAA2 & 51 & 170 & 2 & 0 & 0.012 & 0.0108 \\
\hline PRKAA2 & 85 & 170 & 3 & 8.00E-04 & 0.016 & 0.0104 \\
\hline PRKAA2 & 119 & 170 & 4 & 0.0012 & 0.012 & 0.0116 \\
\hline PRKAA2 & 153 & 170 & 8 & 0.0016 & 0.0824 & 0.0088 \\
\hline VLDLR & 7 & 70 & 5 & 0.1172 & 0.0084 & 0.0128 \\
\hline VLDLR & 21 & 70 & 6 & 0.1168 & 0.0064 & 0.0924 \\
\hline $\operatorname{VLDLR}^{\dagger}$ & 35 & 70 & 7 & 0.1424 & 0.0296 & 0.1356 \\
\hline VLDLR & 49 & 70 & 11 & 0.1728 & 0.0716 & 0.1688 \\
\hline VLDLR & 63 & 70 & 31 & 0.1044 & 0.0604 & 0.152 \\
\hline VLDLR & 12 & 120 & 3 & 0.2704 & 0.052 & 0.0484 \\
\hline VLDLR & 36 & 120 & 3 & 0.2896 & 0.0852 & 0.1124 \\
\hline VLDLR & 60 & 120 & 4 & 0.3 & 0.0368 & 0.1668 \\
\hline VLDLR & 84 & 120 & 6 & 0.2452 & 0.1156 & 0.226 \\
\hline VLDLR & 108 & 120 & 15 & 0.2536 & 0.22 & 0.226 \\
\hline VLDLR & 17 & 170 & 2 & 0.4536 & 0.012 & 0.0064 \\
\hline VLDLR & 51 & 170 & 2 & 0.498 & 0.0096 & 0.0092 \\
\hline VLDLR & 85 & 170 & 3 & 0.2124 & 0.0036 & 0.0132 \\
\hline VLDLR & 119 & 170 & 4 & 0.4448 & 0.0596 & 0.0232 \\
\hline VLDLR & 153 & 170 & 8 & 0.3468 & 0.1328 & 0.0428 \\
\hline
\end{tabular}

Note: ${ }^{\dagger}$ We selected the $r_{1}$ and $r_{2}$ values for the STEPP analysis.

\section{SUPPLEMENTARY TABLE S2}

Pairwise correlation analysis of PRKAA2, HAND2-AS1, and VLDLR

\begin{tabular}{lll}
\hline Gene pairs & $\boldsymbol{P}$-value & Spearman's rank correlation coefficient $(\boldsymbol{r}$ value $)$ \\
\hline HAND2.AS1 and PRKAA2 & $<0.001$ & 0.20 \\
PRKAA2 and VLDLR & $<0.001$ & 0.49 \\
HAND2.AS1 and VLDLR & $<0.001$ & 0.34 \\
\hline
\end{tabular}

